\title{
Oxide-based Complementary Inverters with High Gain and NanoWatt Power Consumption
}

DOI:

10.1109/LED.2018.2871053

\section{Document Version}

Accepted author manuscript

Link to publication record in Manchester Research Explorer

\section{Citation for published version (APA):}

Yuan, Y., Yang, J., Hu, Z., Li, Y., Du, L., Wang, Y., Zhou, L., Wang, Q., Song, A., \& Xin, Q. (2018). Oxide-based Complementary Inverters with High Gain and NanoWatt Power Consumption. IEEE Electron Device Letters, 1-1. https://doi.org/10.1109/LED.2018.2871053

\section{Published in:}

IEEE Electron Device Letters

\section{Citing this paper}

Please note that where the full-text provided on Manchester Research Explorer is the Author Accepted Manuscript or Proof version this may differ from the final Published version. If citing, it is advised that you check and use the publisher's definitive version.

\section{General rights}

Copyright and moral rights for the publications made accessible in the Research Explorer are retained by the authors and/or other copyright owners and it is a condition of accessing publications that users recognise and abide by the legal requirements associated with these rights.

\section{Takedown policy}

If you believe that this document breaches copyright please refer to the University of Manchester's Takedown Procedures [http://man.ac.uk/04Y6Bo] or contact uml.scholarlycommunications@manchester.ac.uk providing relevant details, so we can investigate your claim.

\section{OPEN ACCESS}




\title{
Oxide-based Complementary Inverters with High Gain and NanoWatt Power Consumption
}

\author{
Yuzhuo Yuan, Jin Yang, Zhenjia Hu, Yunpeng Li, LuLu Du, Yiming Wang, Li Zhou, Qingpu Wang, \\ Aimin Song, Senior Member, IEEE, and Qian Xin
}

\begin{abstract}
Oxide semiconductors are ideal candidates for flexible and transparent electronics. Here, we report complementary inverters based on p-type tin monoxide and n-type indium-gallium-zinc-oxide thin-film transistors. The inverters have a gain of 63 at a supply voltage, $V_{\mathrm{DD}}$, of $1.5 \mathrm{~V}$ with a maximum static power consumption of $15.6 \mathrm{nW}$, and a gain of 226 at a $V_{\mathrm{DD}}$ of $3.0 \mathrm{~V}$ with a maximum power consumption of $\mathbf{2 4 1 . 2}$ nW. A five-stage ring oscillator (RO) based on the complementary inverters are able to operate at $1.04 \mathrm{kHz}$, with full amplitude oscillations at a $V_{D D}$ of $1.5 \mathrm{~V}$. All the inverters and $R O$ are fabricated on silicon wafers but at a maximum processing temperature of $225^{\circ} \mathrm{C}$, so that the results are relevant to possible flexible applications. The extremely low power consumption of nanowatt, high gain, $\mathrm{kHz}$ operation, and possible flexibility of the fabricated complementary components are well suited to meet the requirements of wearable electronics, internet of things technology, etc.
\end{abstract}

Index Terms-Complementary inverter, indium gallium zinc oxide (InGaZnO or IGZO), tin monoxide (SnO), low-power, high gain, ring oscillator (RO), thin-film transistor (TFT).

\section{INTRODUCTION}

$\mathrm{O}$ xide semiconductors have been drawing much attention for their high carrier mobility $\left(\sim 1-100 \mathrm{~cm}^{2} \mathrm{~V}^{-1} \mathrm{~s}^{-1}\right)$, visible light transparency, low and even room temperature processability, and are therefore ideal candidates for flexible and transparent electronics. [1-4] Complementary inverters based on oxide semiconductor thin film transistors (TFTs) are basic building blocks of digital circuits that are essential in the emerging applications such as wearable electronics and internet of things (IoT) technology.

Recently, inverters based on unipolar n-type oxide like indium gallium zinc oxide (InGaZnO or IGZO) [5, 6], indium

This work was financed by the National Key Research and Development Program of China (Grant Nos.2016YFA0301200 and 2016YFA0201800), the National Natural Science Foundation of China (Grant No. 11374185), Engineering and Physical Sciences Research Council (EPSRC) (Grant No. EP/N021258/1), China Postdoctoral Science Foundation funded project (2016M590634), the Key Research and Development Program of Shandong Province (2017GGX10111 and 2017GGX10121), Shenzhen Projects of Science and Technology (JCYJ20170818101939090), and the Fundamental Research Funds of Shandong University (2016WLJH44). (Corresponding author: Qian Xin.)

Y. Yuan, J. Yang, Z. Hu, Y. Li, L. Du, Y. Wang, L. Zhou, Q. Wang, A. Song, and Q. Xin are with the Centre of Nanoelectronics, State Key Laboratory of Crystal Materials, and School of Microelectronics, Shandong University, Jinan 250100, China (e-mail:xinq@sdu.edu.cn). (Yuzhuo Yuan and Jin Yang are co-first authors.)

Y. Yuan, J. Yang, Z. Hu, Y. Li, L. Du, Y. Wang, and Q. Xin are with the Shenzhen Institute of Shandong University, Shenzhen, 518057, China.

A. Song is with the School of Electrical and Electronic Engineering, University of Manchester, Manchester M13 9PL, UK. gallium oxide [7], and zinc oxide [8,9], and ambipolar tin monoxide $[10,11]$ have been demonstrated. However, these inverters commonly have problems of large size, non-full amplitude output voltage swings, low noise margin level, and high power consumptions. Complementary inverter composed of a p-type and an n-type TFTs can well solve such problems. However, there is limited development of high performance p-type oxides [12]. P-type carbon nanotubes (CNTs) [13, 14], organic semiconductors[15, 16], poly-silicon[17, 18], and metal compound $[19,20]$, are developed to construct complementary inverters with n-type oxides. However, the process compatibility, thermal stability, p-type purity, flexibility, and performances such as supply voltage, gain, and noise margin level are commonly unsatisfactory. Among the reported limited p-type oxides, $\mathrm{SnO}$ has been regarded as the most promising due to its high field-effect mobility[21], high stability in ambient air [22,23], and high on/off current ratio for TFTs based on them [22, 24, 25]. Thereby, complementary inverters based on p-type $\mathrm{SnO}$ and n-type oxides, e.g. IGZO, are highly desirable for the next generation of flexible/transparent circuits with low supply voltages high performance [26-28].

To date, the supply voltage of the reported oxides-based inverters still need to be further reduced to meet the requirements of battery-powered or wireless radio-frequency (RF) powered wearable electronics, and IoT technology. Most reported complementary inverters have power consumption in $\mu \mathrm{W}$ level[13-15, 18-20, 26-29]. Only very limited inverters have power consumptions in $\mathrm{nW}$ level, however, the low voltage-gains (of $\leqslant 20$ ) highly limit their applications $[16,30]$.

In this work, we have developed complementary inverters based on p-type $\mathrm{SnO}$ and n-type IGZO with rather low power consumption of 15.6 241.2 $\mathrm{nW}$, and high gains of 63 226 at low supply voltages of $1.5 \sim 3.0 \mathrm{~V}$. In addition, these inverters show high noise margins and high logic-swing output. A ring oscillator (RO) based on the complementary inverters was also fabricated to illustrate its dynamic characteristics in different supply voltages of $1.5 \sim 4.5 \mathrm{~V}$.

\section{EXPERIMENTAL}

Figure 1(a) shows the schematic diagram of the fabricated complementary inverters. Si wafers with 300-nm-thick thermally grown $\mathrm{SiO}_{2}$ were used as the substrates. First, 5-nm-thick Ti for adhesion and 30-nm-thick Au as the gate electrode were deposited by e-beam evaporation and patterned by photolithography. 7.5 -nm-thick $\mathrm{Al}_{2} \mathrm{O}_{3}$ gate dielectric was 
then deposited by atomic layer deposition at a substrate temperature of $100{ }^{\circ} \mathrm{C}$ and patterned by photolithography and reactive ion etching. 20-nm-thick p-type $\mathrm{SnO}$ was deposited by radio-frequency $(\mathrm{RF})$ magnetron sputtering with $\mathrm{Sn}$ target at room temperature (RT). The RF power, working pressure, and oxygen partial pressure $\left(\mathrm{O}_{2} /\left(\mathrm{O}_{2}+\mathrm{Ar}\right)\right)$ are $50 \mathrm{~W}, 5.7 \mathrm{mTorr}$, and $3.1 \%$, respectively. The sample was then post-annealed at $225{ }^{\circ} \mathrm{C}$ for $2 \mathrm{~h}$ in ambient air. Then, 16-nm-thick IGZO was $\mathrm{RF}$-sputtered with a power of $90 \mathrm{~W}$, a deposition pressure of 3.6 mTorr, in Ar atmosphere at RT. 30-nm-thick Ti was deposited by e-beam evaporation and patterned by photolithography as the source/drain contacts. The width to length ratios of $\mathrm{SnO}$ and IGZO channels are $60 \mu \mathrm{m} / 20 \mu \mathrm{m}$ and $20 \mu \mathrm{m} / 20 \mu \mathrm{m}$, respectively. The sample was then annealed at $150{ }^{\circ} \mathrm{C}$ for $1 \mathrm{~h}$ in ambient air. The current-voltage $(I-V)$ characteristics of the individual TFTs and complementary inverters were characterized at RT in dark by Agilent B2902A source/measure unit. The output waveform of the five-stage RO was measured by Keysight MSOX6004A mixed signal oscilloscope.

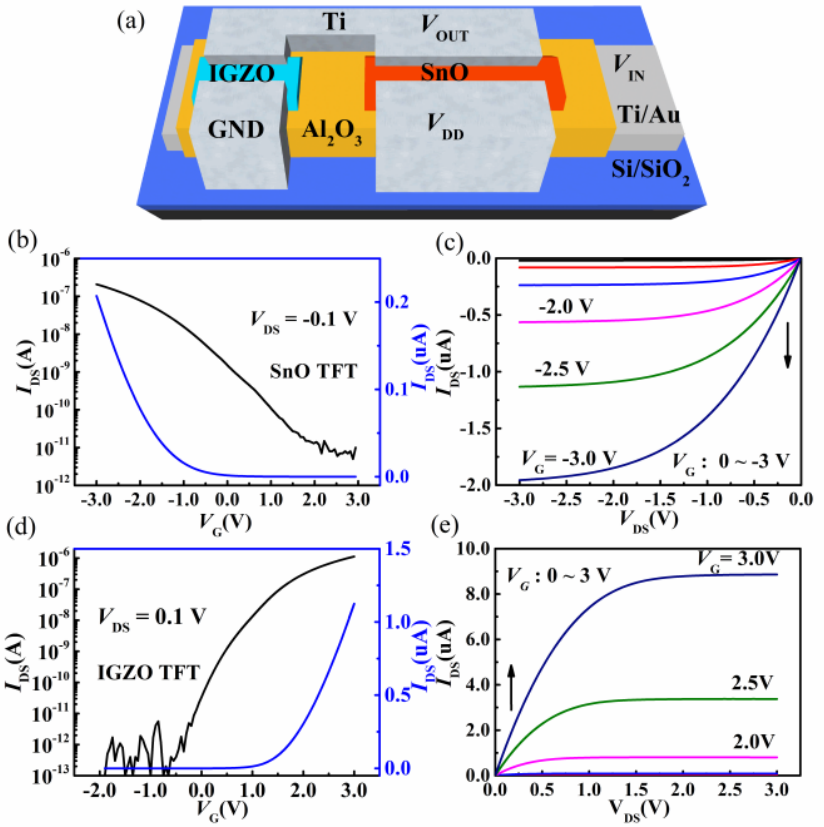

Fig. 1. Schematic view of a complementary inverter based on $\mathrm{SnO}$ and IGZO TFTs on a $\mathrm{Si} / \mathrm{SiO}_{2}$ substrate (a). transfer (b) (d) and output (c)(e) characteristics of the p-type $\mathrm{SnO}$ and the n-type IGZO TFT TFT, respectively.

\section{RESULTS AND DISCUSSION}

Figure 1(b) and (d) shows the transfer characteristics of the p-type SnO and n-type IGZO TFTs at the drain voltage of -0.1 and $0.1 \mathrm{~V}$, respectively. The $\mathrm{SnO}$ and IGZO TFTs exhibit linear-mobility of 0.60 and $12.08 \mathrm{~cm}^{2} \mathrm{~V}^{-1} \mathrm{~S}^{-1}$, a sub-threshold swing $(S S)$ of 0.75 and $0.24 \mathrm{~V} /$ decade, a threshold voltage $\left(V_{\mathrm{TH}}\right)$ of -1.61 and $1.87 \mathrm{~V}$, and an on/off current ratio of $1.50 \times 10^{4}$ and $2.15 \times 10^{6}$, respectively. The output curves shown in Fig. 1(c) and (e) indicate clear current saturations and ohmic contacts between the source/drain electrodes and the active layers.

Figure 2(a) shows the schematic diagram of the complementary inverter (inset) are the static voltage transfer characteristics (VTCs), indicating almost ideal rail-to-rail output voltage behavior. The threshold voltage of the inverter, where $V_{\text {OUT }}=V_{\text {IN }}$, is found to be $0.80,1.17,1.30$, and $1.47 \mathrm{~V}$ at different power supply voltages, $V_{\mathrm{DD}}$, of $1.5,2.0,2.5$, and $3.0 \mathrm{~V}$, respectively, and all are very close to the ideal value, half value of the $V_{\text {DD }}$. The ultrathin $7.5 \mathrm{~nm}$ high- $\kappa$ dielectric $\mathrm{Al}_{2} \mathrm{O}_{3}$ layer contributes to the low supply voltages of $1.5 \sim 3.0 \mathrm{~V}$, which are extremely desirable for battery-powered or wireless RF powered circuits.

The values of noise margin high $N M_{\mathrm{H}}$ and noise margin low $N M_{\mathrm{L}}$, defined as $N M_{\mathrm{H}}=V_{\mathrm{OH}}-V_{\mathrm{IH}}$ and $N M_{\mathrm{L}}=V_{\mathrm{IL}}-V_{\mathrm{OL}}$, respectively, are summarized in Table I, where $V_{\mathrm{IH}}$ and $V_{\mathrm{IL}}$ are the input voltage values with the slopes of VTCs equal to -1 , $V_{\mathrm{OH}}$ is the output-high voltage and $V_{\mathrm{OL}}$ is the output-low voltage. Both $N M_{\mathrm{H}}$ and $N M_{\mathrm{L}}$ are close to the ideal value of $V_{\mathrm{DD}} / 2$, indicating excellent noise performance.

Figure 2(b) shows that the inverter has very high output voltage gain, $\left|\mathrm{d} V_{\text {OUT }} / \mathrm{d} V_{\text {IN }}\right|$, of $63 \sim 226$ when operated at $V_{\mathrm{DD}}$ of 1.5 3.0 V, as also shown in Table I. Figure 3(a) summarizes the output voltage gains of the reported complementary inverters based on new generation semiconductors including CNTs, 2-dimentional materials, oxides, and metal compounds. Comparing to the reported inverters with gains below 160 [15], the inverter in this work reach the highest gain of 226 at $V_{\mathrm{DD}}$ of $3.0 \mathrm{~V}$. The high gain is mainly attributed to the low $S S$ originated from the high channel interface quality and low trap state density in the channels. The high gain and large noise margin of inverters ensure high reliability for the logic gates and complex circuits based on them.

TABLE I

PROPERTIES OF THE INVERTER AT DIFFERENT SUPPLy VOLTAGES

\begin{tabular}{ccccccc}
\hline \hline$V_{\mathrm{DD}}$ & $N M_{\mathrm{L}}$ & $N M_{\mathrm{H}}$ & $\mid$ Gain $\mid$ & $P_{\min }$ & $P_{\max }$ & $\mid$ Gain $\mid P_{\max }$ \\
$(\mathrm{V})$ & $(\mathrm{V})$ & $(\mathrm{V})$ & $(\mathrm{V} / \mathrm{V})$ & $(\mathrm{pW})$ & $(\mathrm{nW})$ & $((\mathrm{V} / \mathrm{V}) / \mathrm{nW})$ \\
1.5 & 0.68 & 0.59 & 63 & 2 & 15.6 & 4.0 \\
2.0 & 0.87 & 0.86 & 123 & 19 & 56.6 & 2.2 \\
2.5 & 1.05 & 1.43 & 189 & 47 & 143.3 & 1.3 \\
3.0 & 1.17 & 1.79 & 226 & 8100 & 241.2 & 0.9 \\
\hline \hline
\end{tabular}
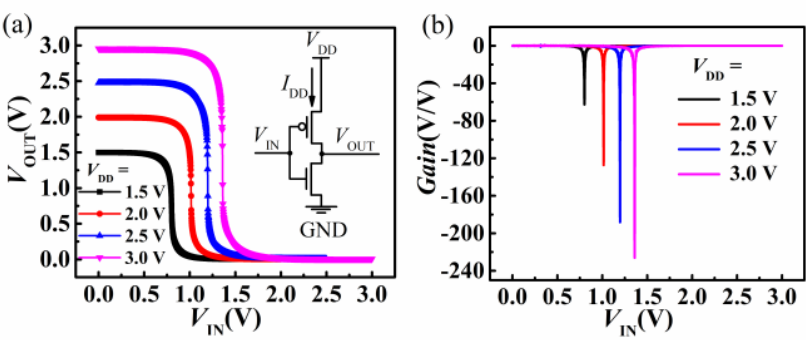

Fig. 2. Static voltage transfer characteristics (a) and voltage gains (b) of inverters with aspect ratios $N=(W / L) \mathrm{p} /(W / L) \mathrm{n}$ and $N=3$ at $V_{\mathrm{DD}}$ of $1.5,2.0,2.5$, and $3.0 \mathrm{~V}$.

Figure 3(b) displays the drain current-voltage $\left(I_{\mathrm{DD}}-V_{\mathrm{IN}}\right)$ output curves of the inverter. $P_{\min }$ and $P_{\max }$, which are the minimum static power consumption before switching and the maximum static consumption occurring at the switching point, respectively, are used to fully evaluate the static power consumption, as shown in Table I. $P_{\min }$ can even reach to $\mathrm{pW}(2$ $\mathrm{pW}$ for $V_{\mathrm{DD}}$ of $1.5 \mathrm{~V}$ ) due to extremely low off current of TFTs based on IGZO and $\mathrm{SnO}$ with wide bandgaps. $P_{\max }$ is found to be as low as $15.6 \sim 241.2 \mathrm{nW}$ at $V_{\mathrm{DD}}$ of $1.5 \sim 3.0 \mathrm{~V}$, indicating rather low power consumption during switching.

Figure 3(c) summarizes the $V_{\mathrm{DD}}$ of the above mentioned reported inverters [13-20,26-39], commonly in range of 2 100 
$\mathrm{V}$. Our inverter has realized the lowest $V_{\mathrm{DD}}$ of $1.5 \mathrm{~V}$, with yet high performance. Such low $V_{\mathrm{DD}}$ lead to significantly low power consumption.

In computer science, energy efficiency ratio "performance per watt" is commonly used to evaluate the computation rate of In this work, we introduce the voltage-gain per nanowatt consumed, $\mid$ Gain $\mid / P_{\max }$, to evaluate the energy efficiency of the inverter during switching. Fig.3(d) summarized the $\mid$ Gain $\mid / P_{\max }$ of the above mentioned reported complementary inverters, and it's clear that our inverter achieves the most effective performance per watt of 4.0. (a)

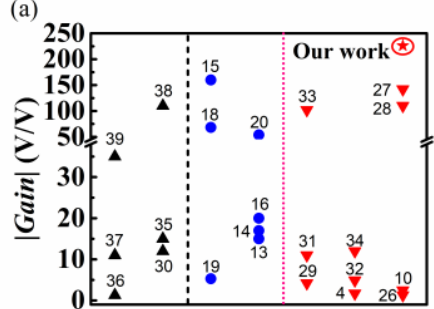

(c)

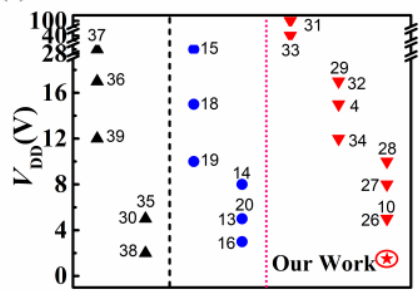

(b)

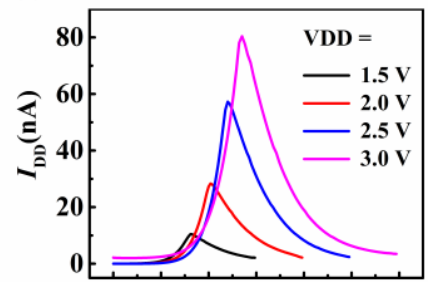

(d) a computer architecture or hardware per every watt consumed.

output, $V_{\text {OUT }}$, at an operating frequency of $1000 \mathrm{~Hz}$ are shown in Fig. 4(b) and (c), respectively. The oscillation frequency, $f$, of the ring oscillator increases from 1.04 to $8.16 \mathrm{KHz}$ with $V_{\mathrm{DD}}$ increasing from 1.5 to $4.5 \mathrm{~V}$, as shown in Fig. 4(d) and (e). The stage delay of the RO, calculated as $1 / 10 f$, is found to be $12 \sim 66$ $\mu$ with $V_{\mathrm{DD}}$ of $4.5 \sim 1.5 \mathrm{~V}$ and the whole circuit power current of $24.63 \sim 0.74 \mu \mathrm{A}$.

\section{CONCLUSION}

In summary, complementary inverters composed of p-type $\mathrm{SnO}$ and n-type IGZO TFTs with rather low supply voltages of 1.5 3.0 V, high gains up to 226 , and high noise margin, have been fabricated via low-temperature (maximum $225{ }^{\circ} \mathrm{C}$ ) process. These inverters with high electrical performance achieve rather low maximum static power consumptions of $15.6 \sim 241.2 \mathrm{nW}$ with supply voltages of $1.5 \sim 3.0 \mathrm{~V}$. The results would inspire reliable circuit designs and fabrications with low voltage, low power consumption, and flexibility, such as IoT technology and wearable/portable electronics.

\section{REFERENCES}

[1] J. S. Park, W.-J. Maeng, H.-S. Kim, and J.-S. Park, "Review of recent developments in amorphous oxide semiconductor thin-film transistor devices," Thin Solid Films, vol. 520, no. 6, pp. 1679-1693, 2012. DOI: 10.1016/j.tsf.2011.07.018

[2] L. Petti, N. Münzenrieder, C. Vogt, H. Faber, L. Büthe, G. Cantarella, F. Bottacchi, T. D. Anthopoulos, and G. Tröster, "Metal oxide semiconductor thin-film transistors for flexible electronics," Applied Physics Reviews, vol. 3, no. 2, pp. 021303, 2016. DOI: 10.1063/1.4953034

Fig. 3. Summary of $V_{\mathrm{DD}}$ (a), static voltage gains (c), and performance per watt (d) of the reported complementary inverters based on carbon nanotubes or 2-dimentional materials (marked as up triangle in black), n-type oxides and p-type non-oxide semiconductors (marked as circles in blue), n-type oxides and p-type oxides (marked as down triangle in red), and our invertor (marked as star in red). (b) Drain current-voltage $\left(I_{\mathrm{DD}}-V_{\mathrm{IN}}\right)$ output curves of our inverter at different $V_{\mathrm{DD}}$ of $1.5 \sim 3.0 \mathrm{~V}$. (a)

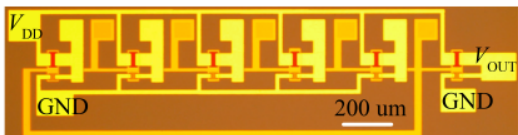

(b)

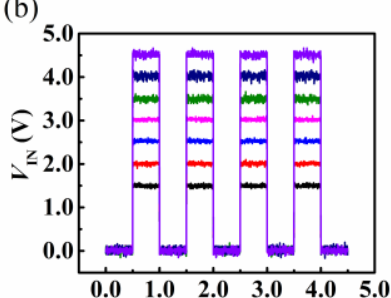

(d)

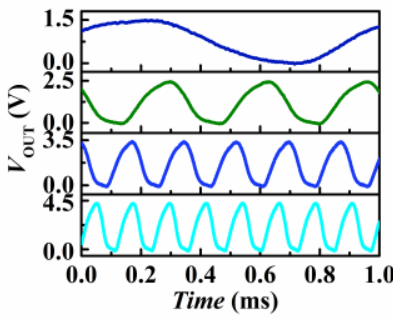

(c)

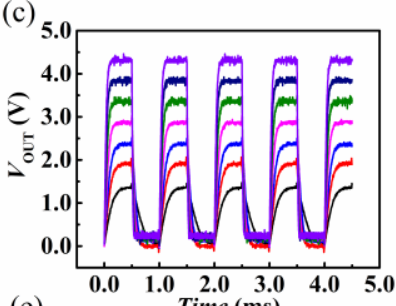

(e)

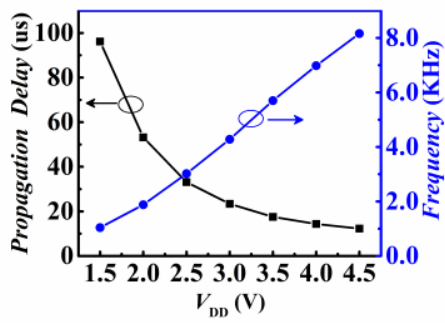

Fig. 4. (a) Layout of the five-stage complementary ring oscillator (RO) with an output buffer. Input (b) and output (c) characteristics of the composed inverters. (d) Output voltage of the RO as a function of time at different VDD. (e) Oscillation frequency and propagation delay as a function of $V_{\mathrm{DD}}$ for the RO.

Figure 4(a) shows the layout of the 5-stage RO with an output buffer. The input pulse, $V_{\mathrm{IN}}$, and the corresponding
[3] Z. Wang, P. K. Nayak, J. A. Caraveo-Frescas, and H. N. Alshareef, "Recent Developments in p-Type Oxide Semiconductor Materials and Devices," Adv Mater, vol. 28, no. 20, pp. 3831-92, May, 2016. DOI: 10.1002/chin.201627243

[4] E. Fortunato, P. Barquinha, and R. Martins, "Oxide semiconductor thin-film transistors: a review of recent advances," Adv Mater, vol. 24, no. 22, pp. 2945-86, Jun 12, 2012. DOI: 10.1002/adma.201103228

[5] H. W. Luo, Patrick; Lunardi, Leda; Muth, John F, "Transparent IGZO-Based Logic Gates," IEEE Electron Device Letters, vol. 33, no. 5, pp. 673-675, 2012. DOI: 10.1109/LED.2012.2186784

[6] X. G. Li, Di; Mativenga, Mallory; Jang, Jin, "High-Speed Dual-Gate a-IGZO TFT-Based Circuits With Top-Gate Offset Structure," IEEE Electron Device Letters, vol. 35, no. 4, pp. 461-463, 2014. DOI: 10.1109/LED.2014.2305665

[7] R. E. Presley, D. Hong, H. Q. Chiang, C. M. Hung, R. L. Hoffman, and J. F. Wager, "Transparent ring oscillator based on indium gallium oxide thin-film transistors," Solid-State Electronics, vol. 50, no. 3, pp. 500-503, 2006. DOI: $10.1016 /$ j.sse.2006.02.004

[8] J. Sun, D. A. Mourey, D. Zhao, and T. N. Jackson, "ZnO Thin Film, Device, and Circuit Fabrication using Low-Temperature PECVD Processes," Journal of Electronic Materials, vol. 37, no. 5, pp. 755-759, 2007. DOI: 10.1007/s11664-007-0362-7

[9] J. M. Sun, Devin A.; Zhao, Dalong; Park, Sung Kyu; Nelson, Shelby F.; Levy, David H.; Freeman, Diane; Cowdery-Corvan, Peter; Tutt, Lee; Jackson, Thomas N, "ZnO Thin-Film Transistor Ring Oscillators with31-ns Propagation Delay," IEEE Electron Device Letters, vol. 29, no. 7, pp. 721-723, 2008. DOI: 10.1109/LED.2008.923206

[10] K. Nomura, T. Kamiya, and H. Hosono, "Ambipolar oxide thin-film transistor," Adv Mater, vol. 23, no. 30, pp. 3431-4, Aug 9, 2011. DOI: 10.1002/adma.201101410

[11] L. Yan Liang, H. Tao Cao, X. Bo Chen, Z. Min Liu, F. Zhuge, H. Luo, J. Li, Y. Cheng $\mathrm{Lu}$, and W. Lu, "Ambipolar inverters using $\mathrm{SnO}$ thin-film transistors with balanced electron and hole mobilities," Applied Physics Letters, vol. 100, no. 26, pp. 263502, 2012. DOI: 10.1063/1.4731271

[12] Y. Ogo, H. Hiramatsu, K. Nomura, H. Yanagi, T. Kamiya, M. Hirano, and H. Hosono, "p-channel thin-film transistor using p-type oxide 
semiconductor, SnO,” Applied Physics Letters, vol. 93, no. 3, pp. 032113, 2008. DOI: $10.1063 / 1.2964197$

[13] H. Chen, Y. Cao, J. Zhang, and C. Zhou, "Large-scale complementary macroelectronics using hybrid integration of carbon nanotubes and IGZO thin-film transistors," Nat Commun, vol. 5, pp. 4097, Jun 13, 2014. DOI: 10.1038/ncomms5097

[14] P. Vuttipittayamongkol, F. Wu, H. Chen, X. Cao, B. Liu, and C. Zhou, "Threshold voltage tuning and printed complementary transistors and inverters based on thin films of carbon nanotubes and indium zinc oxide," Nano Research, vol. 8, no. 4, pp. 1159-1168, 2014. DOI: 10.1007/s12274-014-0596-7

[15] J. B. Kim, C. Fuentes-Hernandez, S. J. Kim, S. Choi, and B. Kippelen, "Flexible hybrid complementary inverters with high gain and balanced noise margins using pentacene and amorphous InGaZnO thin-film transistors," Organic Electronics, vol. 11, no. 6, pp. 1074-1078, 2010. DOI: 10.1016/j.orgel.2010.03.008

[16] M. S. Oh, K. Lee, K. H. Lee, S. H. Cha, J. M. Choi, B. H. Lee, M. M. Sung, and S. Im, "Transparent Photo-Stable Complementary Inverter with an Organic/Inorganic Nanohybrid Dielectric Layer," Advanced Functional Materials, vol. $19, \quad$ no. 5, pp. 726-732, 2009. DOI: 10.1002/adfm.200801155

[17] M. B. Wu, Xiang-Zheng; Sturm, J. C.; Wagner, S, “Complementary Metal Oxide Semiconductor Thin Film Transistor Circuits From a High Temperature Polycrystalline Silicon Process on Steel Foil Substrates," IEEE Transactions on Electron Devices, vol. 49, no. 11, pp. 1993-2000, 2002. DOI: 10.1109/TED.2002.804702

[18] C. Y. Chen, Bo-Ru; Liu, Chuan; Zhou, Xing-Yu; Hsu, Yuan-Jun; Wu, Yuan-Chun; lm, Jang-Soon; Lu, Po-Yen; Wong, Man; Kwok, Hoi-Sing; Shieh, Han-Ping D, "Integrating Poly-Silicon and InGaZnO Thin-Film Transistors for CMOS Inverters," IEEE Transactions on Electron Devices, vol. 64, no. 9, pp. 3668-3671, 2017. DOI: 10.1109/TED.2017.2731205

[19] W. E. W. Bowen, Weiming; Phillips, Jamie D, "Complementary Thin-Film Electronics Based on n-Channel $\mathrm{ZnO}$ and p-Channel ZnTe," IEEE Electron Device Letters, vol. 30, no. 12, pp. 1314-1316, 2009. DOI: 10.1109/LED.2009.2033949

[20] A. Daus, S. Han, S. Knobelspies, G. Cantarella, C. Vogt, N. Munzenrieder, and G. Troster, "Flexible CMOS electronics based on p-type Ge2Sb2Te5 and n-type InGaZnO4 semiconductors," pp. 8.1.1-8.1.4, 2017. DOI: 10.1109/IEDM.2017.8268349

[21] J. A. Caraveo-Frescas, and H. N. Alshareef, "Transparent p-type SnO nanowires with unprecedented hole mobility among oxide semiconductors," Applied Physics Letters, vol. 103, no. 22, pp. 222103 , 2013. DOI: $10.1063 / 1.4833541$

[22] Y.-J. Han, Y.-J. Choi, C.-Y. Jeong, D. Lee, S.-H. Song, and H.-I. Kwon, "Environment-Dependent Bias Stress Stability of P-Type SnO Thin-Film Transistors," IEEE Electron Device Letters, vol. 36, no. 5, pp. 466-468, 2015. DOI: 10.1109/LED.2015.2409854

[23] Y.-J. Han, Y.-J. Choi, I.-T. Cho, S. H. Jin, J.-H. Lee, and H.-I. Kwon, "Improvement of Long-Term Durability and Bias Stress Stability in p-Type SnO Thin-Film Transistors Using a SU-8 Passivation Layer," IEEE Electron Device Letters, vol. 35, no. 12, pp. 1260-1262, 2014. DOI: 10.1109/LED.2014.2363879

[24] S.-D. Bae, S.-H. Kwon, H.-S. Jeong, and H.-I. Kwon, "Demonstration of high-performance p-type tin oxide thin-film transistors using argon-plasma surface treatments," Semiconductor Science and Technology, vol. 32, no. 7, pp. 075006, 2017. DOI: 10.1088/1361-6641/aa72b8

[25] E. Fortunato, and R. Martins, "Where science fiction meets reality? With oxide semiconductors!," physica status solidi (RRL) - Rapid Research Letters, vol. 5, no. 9, pp. 336-339, 2011. DOI: 10.1002/pssr.201105246

[26] J. Zhang, J. Yang, Y. Li, J. Wilson, X. Ma, Q. Xin, and A. Song, "High Performance Complementary Circuits Based on p-SnO and n-IGZO Thin-Film Transistors," Materials (Basel), vol. 10, no. 3, Mar 21, 2017. DOI: $10.3390 / \mathrm{ma} 10030319$

[27] J. Yang, Y. Wang, Y. Li, Y. Yuan, Z. Hu, P. Ma, L. Zhou, Q. Wang, A. Song, and Q. Xin, "Highly Optimised Complementary Inverters Based on p-SnO and n-InGaZnO with High Uniformity," IEEE Electron Device Letters, pp. 1-1, 2018. DOI: 10.1109/LED.2018.2809796

[28] Y. Li, J. Yang, Y. Wang, P. Ma, Y. Yuan, J. Zhang, Z. Lin, L. Zhou, Q. Xin, and A. Song, "Complementary Integrated Circuits Based on p-Type SnO and n-Type IGZO Thin-Film Transistors," IEEE Electron Device Letters, vol. 39, no. 2, pp. 208-211, 2018. DOI: 10.1109/LED.2017.2786237

[29] R. Martins, A. Nathan, R. Barros, L. Pereira, P. Barquinha, N. Correia, R. Costa, A. Ahnood, I. Ferreira, and E. Fortunato, "Complementary metal oxide semiconductor technology with and on paper," Adv Mater, vol. 23 , no. 39, pp. 4491-6, Oct 18, 2011. DOI: 10.1002/adma.201102232
[30] T. Das, X. Chen, H. Jang, I. K. Oh, H. Kim, and J. H. Ahn, "Highly Flexible Hybrid CMOS Inverter Based on $\mathrm{Si}$ Nanomembrane and Molybdenum Disulfide," Small, vol. 12, no. 41, pp. 5720-5727, Nov, 2016. DOI: $10.1002 /$ smll.201602101

[31] C. Dhananjay, Chih-Wei; Ou, Chun-Wei; Wu, Meng-Chyi; Ho, Zhong-Yo; Ho, Kuo-Chuan; Lee, Shih-Wei, "Complementary inverter circuits based on p-SnO2 and n-In2O3 thin film transistors," Applied Physics Letters, vol. 92, no. 23, 2008. DOI: 10.1063/1.2936275

[32] R. F. P. Martins, A. Ahnood, N. Correia, L. M. N. P. Pereira, R. Barros, P. M. C. B. Barquinha, R. Costa, I. M. M. Ferreira, A. Nathan, and E. E. M. C. Fortunato, "Recyclable, Flexible, Low-Power Oxide Electronics," Advanced Functional Materials, vol. 23, no. 17, pp. 2153-2161, 2013. DOI: 10.1002/adfm.201202907

[33] H. Luo, L. Liang, H. Cao, M. Dai, Y. Lu, and M. Wang, "Control of Ambipolar Transport in SnO Thin-Film Transistors by Back-Channel Surface Passivation for High Performance Complementary-like Inverters," ACS Appl Mater Interfaces, vol. 7, no. 31, pp. 17023-31, Aug 12, 2015. DOI: $10.1021 /$ acsami.5b02964

[34] Y.-S. Li, J.-C. He, S.-M. Hsu, C.-C. Lee, D.-Y. Su, F.-Y. Tsai, and I. C. Cheng, "Flexible Complementary Oxide-Semiconductor-Based Circuits Employing n-Channel $\mathrm{ZnO}$ and p-Channel SnO Thin-Film Transistors," IEEE Electron Device Letters, vol. 37, no. 1, pp. 46-49, 2016. DOI: 10.1109/LED.2015.2501843

[35] Z. Li, D. Xie, R. Dai, J. Xu, Y. Sun, M. Sun, C. Zhang, and X. Li, "High-performance heterogeneous complementary inverters based on n-channel MoS2 and p-channel SWCNT transistors," Nano Research, vol. 10, no. 1, pp. 276-283, 2016. DOI: 10.1007/s12274-016-1286-4

[36] J. Huang, S. Somu, and A. Busnaina, "A molybdenum disulfide/carbon nanotube heterogeneous complementary inverter," Nanotechnology, vol. 23, no. 33, pp. 335203, Aug 24, 2012. DOI: $10.1088 / 0957-4484 / 23 / 33 / 335203$

[37] K.-J. Baeg, H. J. Jeong, S. Y. Jeong, J. T. Han, and G.-W. Lee, "Enhanced ambipolar charge transport in staggered carbon nanotube field-effect transistors for printed complementary-like circuits," Current Applied Physics, vol. 17, no. 4, pp. 541-547, 2017. DOI: 10.1016/j.cap.2017.01.024

[38] J. Pu, K. Funahashi, C. H. Chen, M. Y. Li, L. J. Li, and T. Takenobu, "Highly Flexible and High-Performance Complementary Inverters of Large-Area Transition Metal Dichalcogenide Monolayers," Adv Mater, vol. 28, no. 21, pp. 4111-9, Jun, 2016. DOI: 10.1002/adma.201503872

[39] J. W. Chung, Y. H. Ko, Y. K. Hong, W. Song, C. Jung, H. Tang, J. Lee, M. h. Lee, B.-l. Lee, J.-i. Park, Y. Jin, S. Lee, J. s. Yu, J. Park, and S. Kim, "Flexible nano-hybrid inverter based on inkjet-printed organic and 2D multilayer MoS 2 thin film transistor," Organic Electronics, vol. 15, no. 11, pp. 3038-3042, 2014. DOI: 10.1016/j.orgel.2014.08.003 